\title{
Genetic Structure of Zymoseptoria tritici in Northern France at Region, Field, Plant, and Leaf Layer Scales
}

\author{
Ali Siah, Myriam Bomble, Benoit Tisserant, Thierry Cadalen, Maxime Holvoet, Jean-Louis Hilbert, \\ Patrice Halama, and Philippe Reignault ${ }^{\dagger}$
}

First, second, fourth, fifth, sixth, and seventh authors: Institut Charles Viollette (ICV-EA 7394), ISA, Université de Lille, SFR Condorcet FR CNRS 3417, 48 bd Vauban, BP 41290, F-59014 Lille Cedex, France; and third and eighth authors: Univ. Littoral Côte d'Opale, Unité de Chimie Environnementale et Interactions sur le Vivant (UCEIV-EA 4492), SFR Condorcet FR CNRS 3417, CS 80699, F-62228, Calais Cedex, France.

Accepted for publication 9 April 2018.

\begin{abstract}
Population genetic structure of the worldwide-distributed wheat pathogen Zymoseptoria tritici has been extensively studied at large geographical scales, but to a much less extent at small or local spatial scales. A total of 627 single-conidial fungal isolates were sampled from several locations in northern France (Hauts-de-France Region) to assess fungal genetic structure at region, field, plant, and leaf layer scales, using highly polymorphic microsatellite markers and mating type idiomorphs. Important and overall similar levels of both gene and genotype diversities (gene diversity values of $\geq 0.44$ and haplotype frequencies of $\geq 94 \%$ ) were found at all the examined scales. Such rates of diversity are likely due to an active sexual recombination in the investigated areas, as revealed by equal proportions of the two mating types scored in all sampled populations. Interestingly, a rare occurrence of clones among lesions from a same leaf, as well as among leaves from different plant leaf layers (e.g., upper versus lower leaves), was highlighted, indicating that ascospores

contribute much more than expected to Z. tritici epidemics, compared with pycnidiospores. Population structure and analyses of molecular variance revealed significant genetic differentiation at the regional scale $\left(\mathrm{G}_{\mathrm{ST}}=0.23\right)$ and, as expected, not at the other more local scales $\left(\mathrm{G}_{\mathrm{ST}} \leq\right.$ 0.01). Further analyses using Bayesian and unweighted neighbor-joining statistical methods detected six genetic clusters within the regional population, overall distributed according to the locations from which the isolates were sampled. Neither clear directional relative migration linked to the geographical distribution of the locations, nor isolation by distance, were observed. Separate evolutionary trajectories caused by selection and adaptations to habitat heterogeneity could be the main forces shaping such structuration. This study provides new insights into the epidemiology and the genetic structure of Z. tritici at small local and, for the first time, at single plant and leaf layer scales. Such findings would be helpful in implementing effective control strategies.
\end{abstract}

Septoria tritici blotch (STB) caused by the heterothallic ascomycete fungus Zymoseptoria tritici (synonym Mycosphaerella graminicola) is one of the most devastating foliar diseases on wheat crops worldwide, especially in Europe (O'Driscoll et al. 2014). In France, losses due to STB are estimated each year to 1.7 tons per hectare on average, and yield reductions can reach $50 \%$ when environmental conditions are suitable for disease development (https://www.arvalis-infos.fr/). Z. tritici emerged as a hostspecialized wheat pathogen around 10,000 years ago through host tracking, likely during the domestication of wheat in the Fertile Crescent (Stukenbrock and McDonald 2008). The pathogen was then globally dispersed, as a result of the expansion of wheat cultivation (Banke and McDonald 2005). Because of its economic importance, experimental amenability, and growing interest within scientist and agronomist communities, $Z$. tritici has arose as a model for the order Dothideales (Kema et al. 2008) and was ranked among the top 10 fungal pathogens in the area of molecular plant pathology (Dean et al. 2012). The nuclear genome of Z tritici contains 21 chromosomes, including 13 core chromosomes and a set of eight

†Corresponding author: P. Reignault; E-mail: philippe.reignault@univ-littoral.fr

Funding: This research was conducted in the framework of both ARCir (Actions de Recherche Concertée d'initiative régionale) project supported by the Hautsde-France Regional Council (France) and Dephy Expe Ecophyto project supported by the Hauts-de-France Regional Council and the Interdepartmental organization Office National de l'Eau et des Milieux Aquatiques (France). It has been carried out in the framework of Alibiotech project, which is founded by the European Union, the French State, and the French Region of Hauts-de-France.

(c) 2018 The American Phytopathological Society repeat-rich accessory chromosomes (Goodwin et al. 2011). Z. tritici undergoes both asexual and sexual reproductions in the field. Clonal multiplication occurs mainly during the wheat-growing season, by producing pycnidiospores that are dispersed locally by rain splash and physical contact. During the sexual stage, the pathogen produces, in each ascus, four couples of genetically distinct (with 4:4 mating type ratio) ascospores (Kema et al. 1996), which have the potential to be dispersed over long distances by wind. Ascospores contribute not only to primary initial infections of wheat in the autumn, but also to disease progression during the growing season since sexual reproduction in $Z$. tritici occurs usually throughout the whole year (Duvivier et al. 2013; Hunter et al. 1999). Host resistance against $Z$. tritici is not completely effective in most wheat cultivars. Therefore, disease control relies mainly of the use of conventional fungicides. Nonetheless, the durability of both chemical and genetic control strategies is regularly impacted in the field since $Z$. tritici frequently develops resistance to fungicides and circumvents host resistance (Cheval et al. 2017; Zhong et al. 2017). This is due to its high fitness degree resulting very likely from its frequent sexual reproduction and genetic recombination in the field (El Chartouni et al. 2011; Linde et al. 2002).

Knowledge of population genetic structure is especially useful for better understanding pathogen epidemiology and evolutionary potential. The importance of such information in devising more efficient control strategies against $Z$. tritici has recently been well reviewed (McDonald and Mundt 2016). Genetic structure refers to the patterns of genetic diversity within and between populations, resulting from the interactions among the major forces shaping pathogen evolution, including natural selection, mutation, genetic 
drift, recombination/mating, and migration (Milgroom 2015). In nature, all of these forces interact to determine the course of evolution of a pathogen and to generate the genetic structure of its populations, hence facilitating its adaptation to environmental changes and ecological niches. Usually, pathogens with a mixed reproduction system, a high potential for genotype flow, large effective population sizes, and high mutation rates pose a greatest risk of breaking down resistance genes than pathogens with strict asexual reproduction, low potential for gene flow, small effective population sizes, and low mutation rates (McDonald and Linde 2002).

Z. tritici has been intensively studied for genetic diversity and population structure over the three last decades, and findings provided important insight into the biology, epidemiology, and evolutionary history of the pathogen (McDonald and Mundt 2016). The investigations were performed using a wide range of molecular markers including mating type idiomorphs (Siah et al. 2010; Zhan et al. 2002), random amplified polymorphic DNA (Czembor and Arseniuk 1999), restriction fragment length polymorphism (RFLP) (Linde et al. 2002), amplified fragment length polymorphism (AFLP) (Abrinbana et al. 2010), and microsatellite markers (Gurung et al. 2011). Some studies examining the diversity and structure in Z. tritici populations using mitochondrial DNA-based markers were also undertaken (Siah et al. 2014; Torriani et al. 2011). More recently, a population genomic approach based on whole genome alignments to infer genomic structure and genome wide patterns of selection among isolates of $Z$. tritici was applied (Grandaubert et al. 2017). Most of these studies were set up to assess fungal genetic structure at the country scale or compared populations from different countries (Gurung et al. 2011; Zhan et al. 2003). Overall, these investigations reported high levels of genetic diversity, rates of population differentiation, and gene flow that vary depending on the sampled geographical area and/or the marker used (Abrinbana et al. 2010; El Chartouni et al. 2011; Grandaubert et al. 2017; Gurung et al. 2011; Linde et al. 2002). For instance, molecular profiling of worldwide $Z$. tritici collections using RFLP markers revealed a lack or little structure and very high gene flow between Z. tritici populations at the world scale (Zhan et al. 2003). On the other hand, more recent studies performed using microsatellite or AFLP markers showed significant levels of genetic differentiation in populations from countries such as Iran (Abrinbana et al. 2010), France (El Chartouni et al. 2011), and the United States (Gurung et al. 2011). In France, a characterization of $Z$. tritici population using microsatellite markers and sequences from two housekeeping genes (actin and $\beta$-tubulin) revealed population clustering into three genetic groups (El Chartouni et al. 2011). However, no significant investigation was conducted since then in France to decipher fungal population genetics at smaller scales, and reports on genetic structure of Z. tritici on more localized levels such as a single plant or plant leaf layers (e.g., upper versus lower leaves) are still lacking. This later aspect is of particular importance since it should provide new insights into the epidemiology of the pathogen. Moreover, investigations on the $Z$. tritici genetic diversity at the field level are limited and no study was performed at this scale since Linde et al. (2002), who used RFLP markers. The goal of the present study was thus to assess the Z. tritici population structure in northern France at different spatial scales (region, field, plant, and leaf layer), with a focus on the Hauts-de-France region. This major wheat-growing area of France was chosen because it is the most impacted region by $Z$. tritici epidemics due to its humid and mild climate suitable for wheat growing, but unfortunately also for STB infections. Population characterization was performed by measuring the patterns of both genetic diversity and population structure at each scale, using microsatellite markers. In addition, the potential of fungal sexual recombination was estimated by assessing the frequencies of two fungal mating types (MAT1-1 and MAT1-2) and linkage disequilibrium within populations.

\section{MATERIALS AND METHODS}

Fungal collection and isolation. Six hundred twenty-seven single-conidial isolates of $Z$. tritici were collected in northern France, from the Hauts-de-France region $\left(\sim 12,414 \mathrm{~km}^{2}\right)$. First, 282 isolates were sampled in June 2009 from 12 distinct geographic locations in different representative parts of the region in order to assess the genetic structure of the pathogen at the region scale. Distances between locations ranged from $16 \mathrm{~km}$ (locations 7 and 8 ) to $45 \mathrm{~km}$ (locations 3 and 12), with an average distance between locations of $67 \mathrm{~km}$. In each location, the isolates were randomly collected in a single field from flag leaves of different plants $1 \mathrm{~m}$ apart to each other. Furthermore, a subset of 240 isolates were harvested in June 2016 from two fields of $200 \mathrm{~m} \times 20 \mathrm{~m}$ each located in Lorgies and Tilloy-les-Mofflaines, respectively. In order to have a representative view of fungal populations within the fields, the isolates were sampled in each field from four plots of $30 \mathrm{~m} \times 20 \mathrm{~m}$ each at $10 \mathrm{~m}$ apart. In each plot, 30 isolates were isolated from flag leaves of different plants $1 \mathrm{~m}$ apart to each other, leading to a collection of 120 isolates per field. Finally, 105 additional isolates were obtained in June 2012 from five plants $10 \mathrm{~cm}$ apart to each other in order to examine pathogen genetic structure at the plant and leaf layer scales (Fig. 1). On each leaf, the isolates were collected from different lesions. Only five isolates were obtained from the fourth leaf layer (four isolates from plant 1 and one isolate from plant 3) because of advanced leaf senescence that caused strong contaminations during fungal isolation procedure. All leaves were collected from untreated and naturally infected bread wheat plants, and isolates were obtained from the sampled leaves according to the fungal isolation procedure described by Siah et al. (2010). Once obtained, the isolates were grown on potatoes dextrose agar (PDA) medium and stored at $-80^{\circ} \mathrm{C}$ for further analyses. All isolates from each investigated scale (region, field, plant, and leaf layer) will hereafter be referred to as a collection, and all isolates from each subscale within each collection (location, plot, single plant, or single leaf layer, respectively) will be referred to as a subcollection.

DNA extraction, microsatellite fingerprinting, and mating type determination. Genomic DNA was extracted from 2-week-old PDA-growing culture of each strain, according to Siah et al. (2010). All isolates were fingerprinted using eight microsatellite markers: ST1A4, ST2C10, ST1D7, ST1E3, ST2E4, ST1E7, ST1G7 (Owen et al. 1998), and AC0007 (Goodwin et al. 2007) (Table 1). These markers were chosen because they were found to be polymorphic in preliminary experiments. PCR reactions were performed in a $20-\mu \mathrm{l}$ reaction volume containing $0.05 \mu \mathrm{l}$ of each primer $(20 \mu \mathrm{M}), 1.6 \mu \mathrm{l}$ of $2.5 \mathrm{mM}$ dNTPs, $2 \mu \mathrm{l}$ of $10 \times$ reaction buffer, $3.2 \mu \mathrm{l}$ of $25 \mathrm{mM} \mathrm{MgCl} 2,0.20 \mathrm{U}$ of Taq DNA polymerase (Ampli Taq Gold, Applied Biosystem, Roche), and $2 \mu$ of fungal DNA ( $1 \mathrm{ng} / \mu$ l final DNA concentration). The amplifications were carried out using a Peltier thermal cycler (MJ Research) under the following temperature program: initial denaturation at $94^{\circ} \mathrm{C}$ for $10 \mathrm{~min}$; followed by 40 cycles of $94^{\circ} \mathrm{C}$ for $1 \mathrm{~min}, 58^{\circ} \mathrm{C}$ or $65^{\circ} \mathrm{C}$ for $30 \mathrm{~s}$ (depending on the primer pair used), and $72^{\circ} \mathrm{C}$ for $1 \mathrm{~min}$; with a final extension at $72^{\circ} \mathrm{C}$ for $10 \mathrm{~min}$. After the final cycle, the samples were stored at $4^{\circ} \mathrm{C}$ for further investigations. Amplicons obtained from the 282 isolates obtained at the region scale were separated in a $6 \%$ urea-polyacrylamide gel on a vertical electrophoresis system according to El Chartouni et al. (2011), while PCR products from the 240 and 105 isolates collected at the field, plant, and leaf layer scales, respectively, were separated using capillary array electrophoresis. The separation was performed in multiplex after pooling the amplicons into four pools of two amplicons per pool (Table 1). Within each pool, the primer pair used to amplify each marker was labeled with a fluorescent dye (Applied Biosystems, CA) with either blue (6-FAM) or green (HEX) fluorochromes for a better resolution on the capillary system (Table 1). Mixtures were performed by using $1 \mu \mathrm{l}$ of each pooled-PCR product mixed with 
$10 \mu \mathrm{l}$ of formamide (Sigma-Aldrich, France) and $0.15 \mu \mathrm{l}$ of GeneScan 500 LIZ Size Standard (Applied Biosystems). After a denaturation step at $94^{\circ} \mathrm{C}$ for $10 \mathrm{~min}$, the pooled-PCR products were analyzed in a 3130xl Genetic Analyzer DNA sequencer (Applied Biosystems) at $60^{\circ} \mathrm{C}$ and $1.5 \mathrm{Kv}$. Fluorescent peaks were standardized using the Genescan Analysis software v 3.7.1. The conversion into alleles and the determination of allele sizes were estimated using the software Genotyper (Applied Biosystems). Alleles scored with each microsatellite marker in each collection were summarized in an Excel sheet before being submitted for statistical analyses.

Mating types of the isolates were determined using a multiplex PCR assay, allowing the amplification of partial sequences from the two mating-type idiomorphs (Waalwijk et al. 2002). PCR reactions as well as PCR thermal cycling conditions were performed according to Siah et al. (2010). PCR products were separated by electrophoresis on $1.5 \%$ agarose gels run at $100 \mathrm{~V}$ for $45 \mathrm{~min}$. After ethidium bromide staining and visualizing under UV light, images were captured with a digital camera (Clara Vision, France) and scored manually.

Data analyses. Isolates with the same combination of alleles at all loci (probably clones) were considered as identical multilocus haplotypes and only a single representative multilocus haplotype (unique genotype) was used within subcollections for subsequent analyses, except for genotype diversity analysis. Genotype diversity was estimated by calculating the clonal fraction and the frequency of haplotypes in each collection using the program Arlequin version 3.5.2.2 (Excoffier and Lischer 2010). Gene diversity in each collection was measured with several indices, including the number of different alleles, gene diversity (Nei 1973) and the unbiased gene diversity (Anon 1996), calculated using the GenAlEx version 6.501 program (Peakall and Smouse 2012).

Genetic structure was tested using different approaches. First, the magnitude of genetic differentiation among subcollections, according to each locus, was assessed using several fixation indices including the Wright's $\mathrm{F}$ index $\left(\mathrm{F}_{\mathrm{ST}}\right)$ implemented in GenAlEx version 6.501, the Nei's $\mathrm{G}_{\mathrm{ST}}$ index, a multiallelic analog of $\mathrm{F}_{\mathrm{ST}}$ that is suitable for haploids as well as diploids (Nei 1973), implemented in POPGENE version 1.32 (Yeh et al. 2000), and new standardized estimators of genetic structure, including the Hedrick's standardized fixation index $\mathrm{G}^{\prime \prime}$ ST (Meirmans and Hedrick 2011) and the Jost's standardized fixation index Jost's $D_{\text {est }}$ (Jost 2008), implemented in GenAlEx version 6.501. These different indices were calculated since there was much discussion about the best statistic tool to use when measuring genetic differentiation between or among populations (Jost 2008; Meirmans and Hedrick 2011; Whitlock 2011). In addition, the program GenAlEx version 6.501 was run to calculate both $\mathrm{F}_{\mathrm{ST}}$ and $\Phi_{\mathrm{PT}}$ indices to highlight the amount of population differentiation among pairs of subcollections (locations). $\Phi_{\mathrm{PT}}$ is an analog of standardized $\mathrm{F}_{\mathrm{ST}}$ for haploid data

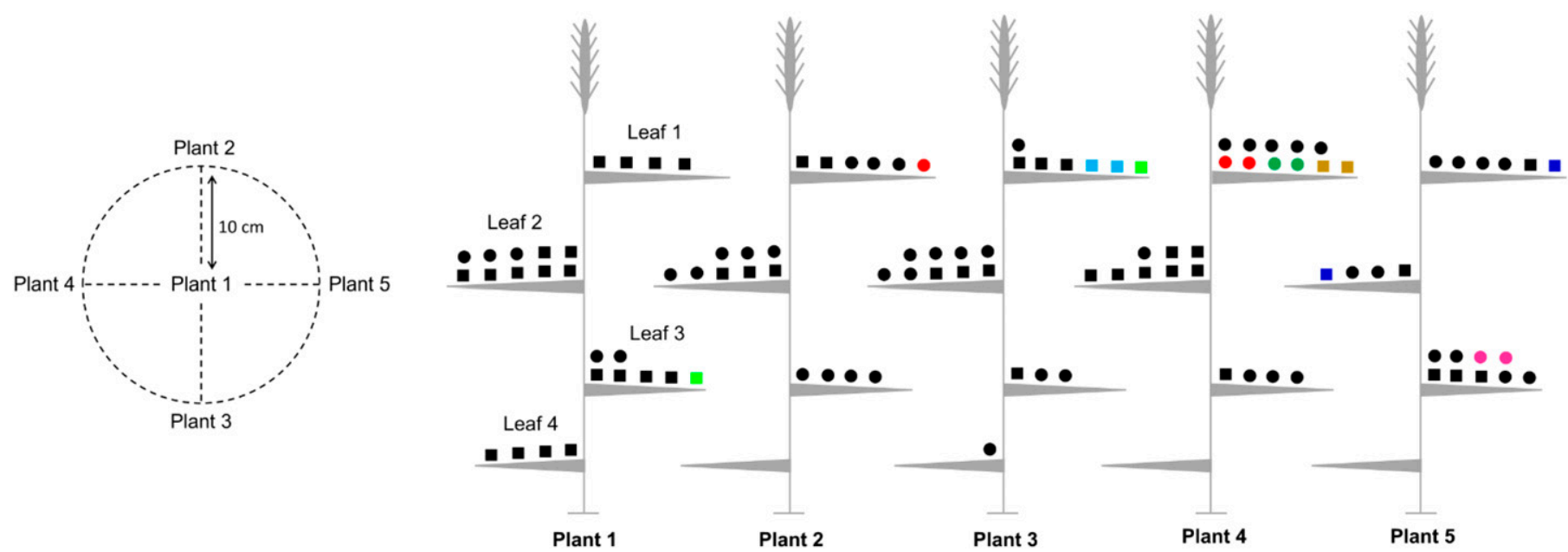

Fig. 1. Spatial distribution of the 105 Zymoseptoria tritici isolates sampled from five wheat plants distanced to each other by $10 \mathrm{~cm}$ and from different layers. Isolates represented in black are unique multilocus haplotypes, while the other isolates indicated by another and same color are identical multilocus haplotypes, i.e., clones (according to microsatellite fingerprinting). MAT1-1 isolates are represented by circles (0) and MAT1-2 isolates are represented by squares (๘). MAT1-1 and MAT1-2 refer to mating types. All isolates were sampled from different lesions within the leaves. The isolates are randomly represented on the leaves since no information was noted regarding the localization of the lesions on the sampled leaves during the fungal isolation procedure.

TABLE 1. Characteristics of the eight pairs of microsatellite primers used in this study

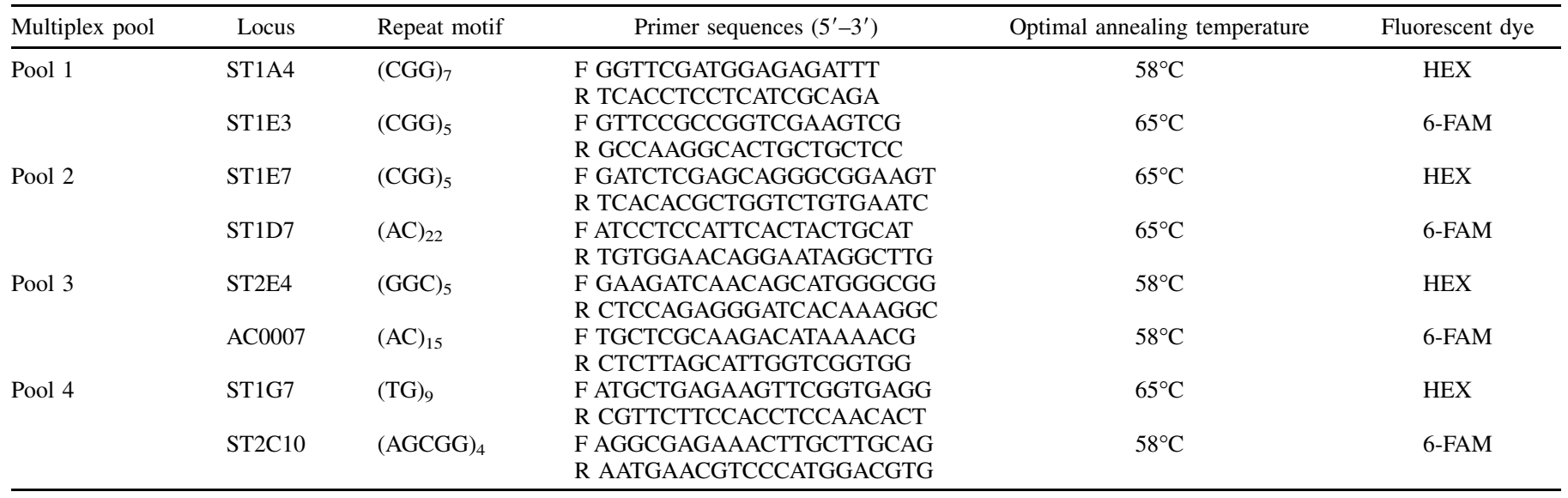


and represents a 0 to 1 scaled estimator of population differentiation (Meirmans 2006; Meirmans and Hedrick 2011). Sources of genetic structure in each collection were investigated using hierarchical analysis of molecular variance (AMOVA) implemented in GenA$1 E x$ version 6.501 , by estimating the degree of genetic differentiation within and among subcollections, using 1,000 permutations.

Fungal population structure was also analyzed using Structure version 2.3.4, a model-based clustering program that uses a Bayesian approach to estimate the number of populations (clusters) and to assign probabilistically individuals to populations (Falush et al. 2003; Pritchard et al. 2000). The analysis was performed without prior information on the subcollections to which the individuals belonged. The admixture model with correlated allele frequencies was applied, with 100,000 iterations of the Markov Monte Carlo Chain (MCMC) used as 'burn-in' that were followed by 1,000,000 MCMC iterations. The data were analyzed with $\mathrm{K}$ ranging from 1 to 13 , with 10 repeat runs for each $\mathrm{K}$. The best estimate of $\mathrm{K}$ was based on $\Delta K$ values calculated from $L n P(D)$, as described in Evanno et al. (2005). This approach reduces the risk of overestimating $\mathrm{K}$ and, therefore, provides a correct estimation of the number of clusters. The Structure Harvester web interface (Earl and vonHoldt 2012) was used to identify the most likely number of occurring clusters (highest $\Delta \mathrm{K}$ value) according to the method of Evanno et al. (2005). Furthermore, a dendrogram estimating genetic clustering of the haplotypes was produced using the unweighted neighbor-joining method based on the dissimilarity matrix (10,000 bootstraps), as implemented in the DARwin version 6.0.014 software (Perrier and Jacquemoud-Collet 2006). In addition, directional relative migration network among the 12 locations of the region scale was determined using the divMigrate-online software using Jost's $D$ $\left(D_{\text {est }}\right)$ as a measure of genetic differentiation (Jost 2008; Sundqvist et al. 2016). This approach provides network plots that visualize patterns of directional relative migration between locations. Finally, the nonparametric Mantel test was applied to determine a potential isolation by distance among the subcollections of the region scale, i.e., to test the correlation between geographical distance between locations and the rates of genetic differentiation. The test was carried out using the GenAlEx version 6.501 software with 1,000 random permutations, with the matrix of pairwise genetic differentiation between locations (with $\Phi_{\mathrm{PT}}$ index), and a matrix of geographic distance obtained from the universal transverse Mercator (UTM) values of the locations.

Random mating in the collections was tested using two approaches. First, the standardized index of association $\left(\mathrm{sI}_{\mathrm{A}}\right)$ was calculated using the LIAN (LInkage ANalysis) version 3.7 web interface (Haubold and Hudson 2000) to test multilocus linkage disequilibrium under the null hypothesis that alleles observed at different loci are unlinked. Significant difference from linkage equilibrium was tested using the Monte Carlo random sampling method (1000 iterations), as implemented in LIAN version 3.7. Then, the potential of sexual reproduction was evaluated by determining whether the frequencies of the two mating types (MAT1-1 and MAT1-2) deviated significantly from the 1:1 ratio, using the $\chi^{2}$ test at $P=0.05$. The two idiomorphs are expected to occur at equal proportions under the scenario of regular cycles of sexual reproduction.

\section{RESULTS}

High and similar levels of both gene and genotype diversities for $Z$. tritici at region, field, plant, and leaf layer scales. A collection of $627 \mathrm{Z}$. tritici isolates sampled from northern France (Hauts-de-France region) at different scales (region, field, plant, and leaf layer) was typed using microsatellite markers to assess genetic diversity and population structure of the pathogen at local spatial scales. All markers were polymorphic in all examined collections. In the regional collection, a total of 83 different alleles was scored over the eight tested loci and the number of amplified alleles per locus ranged from 6 (ST2C10 locus) to 17 (AC0007 locus), with an average of 10.4 alleles per locus. Within the region locations, the average number of different alleles per locus ranged from 3.12 (location 6) to 6.75 (location 4), with an average of 4.21 alleles per locus across all locations (Table 2). When considering the single field fungal collection, 76 distinct alleles were detected over the eight tested loci and the number of observed alleles per locus ranged from 3 (ST1G7 locus) to 23 (ST1D7 locus), with an average of 9.5 alleles per locus. Within the fields, the average number of different alleles per locus ranged from 4.12 (plot 1) to 4.87 (plot 4) in field 1 and from 4.62 (plots 1 and 2) to 4.87 (plot 3) in field 2, with an average of 4.71 alleles per locus per field (Table 2). Finally, in the plant and leaf layer collections, which consisted of the same collection used for both scale investigations, a total of 73 different alleles were highlighted over the eight tested loci and the number of alleles per locus ranged from 3 (ST1G7 locus) to 23 (AC0007 locus), with an average of 9.1 alleles per locus. The average number of different alleles per locus ranged from 4.12 (plant 5) to 5.37 (plant 1) across all plants and from 2.37 (leaf layer 4) to 5.87 (leaf layer 2) over all leaf layers, with an average of 4.72 and 4.87 alleles per locus, per plant and per leaf layer, respectively (Table 2). The low number of alleles observed in the leaf layer 4 was likely due to the very small sample size of isolates, since only five isolates were successfully obtained for this leaf layer during fungal isolation procedure.

Multilocus analysis revealed high and similar amounts of genotype diversity within all tested collections, with 269 (95\%), 231 (96\%), and 99 (94\%) haplotypes identified among the 282, 240, and 105 fungal isolates sampled from the region, field, and both plant and leaf layer scales, respectively (Table 2). Interestingly, in the plant collection, most of the clones detected on the plants were found on the same leaf (four couples of clones occurred on leaf layer 1 among which one clone on both plants 2 and 4, and one couple of clones on leaf layer 3) (Fig. 1). Only two couples of clones occurred on different leaf layers (Fig. 1). The haplotype frequency within subcollections varied slightly in each collection, but this variation could likely be due to the variation in sample size (Table 2).

Allele diversity analyses revealed also high and close levels of gene diversity among the studied collections. The averaged Nei's gene diversity index consisted of $0.47,0.44,0.56$, and 0.54 in collections from the region, field, plant, and leaf layer scales, respectively, with very slight variations among the subcollections in each collection (Table 2). The values of the unbiased gene diversity index (standardized for sample size) were overall slightly higher than those of the Nei's index, but globally display a similar extent of gene diversity when compared with the values of Nei's index (Table 2).

Significant clustering of $Z$. tritici populations at the region scale. All measures of genetic structure showed significant population structure at the region scale and no significant genetic differentiation at the field, plant, and leaf layer scales (Table 3). The values of the different fixation indices $\left(\mathrm{F}_{\mathrm{ST}}, \mathrm{G}_{\mathrm{ST}}, \mathrm{G}\right.$ "' $\mathrm{ST}$, and $\left.D_{\text {est }}\right)$ varied strongly among loci, especially in the region collection, where the highest values for all indices (except for $D_{\text {est }}$ ) were found for the ST2C10 locus and the lowest ones for the ST1E3 locus. However, their value range was overall similar within all collections. Statistical analyses at $P=0.01$ showed that only the region collection showed significant genetic differentiation (at all loci, except ST1E3), with averaged $\mathrm{F}_{\mathrm{ST}}, \mathrm{G}_{\mathrm{ST}}, \mathrm{G}^{\text {" }}{ }_{\mathrm{ST}}$, and $D_{\text {est }}$ values of $0.27,0.23,0.49$, and 0.32 , respectively (Table 3 ). All values of fixation indices did not exceed 0.04 in the field, plant, and leaf layer collections (Table 3). AMOVA confirmed these findings and showed that $25 \%$ of the genetic variation could be explained by differences among subcollections (locations) and $75 \%$ by differences within subcollections in the region collection, while such percentages did not exceed $1 \%$ among subcollections and exceeded 99\% within subcollections in field, plant, and leaf layer collections (Fig. 2). Additional analyses using the Structure software confirmed 
the lack of genetic structure within the field, plant, and leaf layer collections (data not shown).

Pairwise $F_{\mathrm{ST}}$ and $\Phi_{\mathrm{PT}}$ comparisons among subcollections in the region collection revealed significant genetic differentiation between all sampled locations, with $\mathrm{F}_{\mathrm{ST}}$ and $\Phi_{\mathrm{PT}}$ values among locations ranging from 0.03 to 0.26 and from 0.02 to 0.38 , respectively (Table 4). The value range of both fixation indices was overall similar among all locations, and all $\mathrm{F}_{\mathrm{ST}}$ and $\Phi_{\mathrm{PT}}$ comparisons

TABLE 2. Genetic diversity based on eight microsatellite markers in Zymoseptoria tritici subcollections sampled in northern France (Hauts-de-France region) from different scales

\begin{tabular}{|c|c|c|c|c|c|c|c|c|c|c|c|}
\hline Scale & Year of sampling & Location & Abbreviation & Cultivar & $\mathrm{N}^{\mathrm{a}}$ & $\mathrm{H}^{\mathrm{b}}$ & $\mathrm{Na}^{\mathrm{c}}$ & $\mathrm{H}^{\mathrm{d}}$ & $\mathrm{uH}^{\mathrm{e}}$ & $\mathrm{SI}_{\mathrm{A}}{ }^{\mathrm{f}}$ & MATg $^{g}$ \\
\hline \multirow[t]{13}{*}{ Region } & \multirow[t]{13}{*}{2009} & Teteghem & Location 1 & Boisseau & 24 & 24 & 4.25 & 0.47 & 0.49 & 0.00 & $7: 17$ \\
\hline & & Vieille-Eglise & Location 2 & Pireneo & 24 & 23 & 4.37 & 0.49 & 0.51 & 0.04 & $12: 11$ \\
\hline & & Carly & Location 3 & Raspail & 24 & 24 & 5.50 & 0.56 & 0.59 & -0.01 & $14: 10$ \\
\hline & & Campigneulles-les-Grandes & Location 4 & Bermude & 24 & 24 & 6.75 & 0.65 & 0.68 & 0.01 & $11: 13$ \\
\hline & & Campagne-les-Wardrecques & Location 5 & Bermude & 24 & 23 & 3.50 & 0.41 & 0.43 & -0.01 & $14: 9$ \\
\hline & & Troisveaux & Location 6 & Pireneo & 20 & 20 & 3.12 & 0.38 & 0.40 & -0.02 & $11: 9$ \\
\hline & & Warlincourt-les-Pas & Location 7 & Pactole & 24 & 23 & 4.12 & 0.44 & 0.46 & -0.00 & $11: 12$ \\
\hline & & Izel-les-Hameaux & Location 8 & Cordiale & 24 & 20 & 3.62 & 0.38 & 0.40 & 0.03 & $9: 11$ \\
\hline & & Carvin & Location 9 & Cadenza & 24 & 22 & 3.50 & 0.40 & 0.42 & 0.01 & $11: 11$ \\
\hline & & Bapaume & Location 10 & Bermude & 22 & 22 & 3.87 & 0.42 & 0.44 & 0.02 & $9: 13$ \\
\hline & & Marcq-en-Ostrevent & Location 11 & Apache & 24 & 22 & 3.75 & 0.52 & 0.55 & 0.03 & $9: 13$ \\
\hline & & \multirow[t]{2}{*}{ Sautain } & Location 12 & Mixture $^{\text {h }}$ & 24 & 22 & 4.12 & 0.47 & 0.50 & 0.01 & $7: 15$ \\
\hline & & & Total or overall & & 282 & 269 & 4.21 & 0.47 & 0.49 & $0.01 *$ & $125 / 144$ \\
\hline \multirow[t]{11}{*}{ Field } & \multirow[t]{11}{*}{2016} & \multirow[t]{5}{*}{ Lorgies (field 1) } & Plot 1 & Bergamo & 30 & 30 & 4.12 & 0.42 & 0.44 & 0.01 & $13: 17$ \\
\hline & & & Plot 2 & Bergamo & 30 & 27 & 4.75 & 0.47 & 0.49 & 0.02 & $10: 20$ \\
\hline & & & Plot 3 & Terroir & 30 & 28 & 4.25 & 0.40 & 0.42 & -0.01 & $14: 16$ \\
\hline & & & Plot 4 & Terroir & 30 & 30 & 4.87 & 0.43 & 0.45 & -0.00 & $13: 17$ \\
\hline & & & Total or overall & & 120 & 115 & 4.50 & 0.43 & 0.44 & & $50: 70$ \\
\hline & & \multirow[t]{5}{*}{ Tilloy-les-Mofflaines (field 2) } & Plot 1 & Bergamo & 30 & 30 & 4.62 & 0.41 & 0.43 & -0.00 & $15: 15$ \\
\hline & & & Plot 2 & Bergamo & 30 & 30 & 4.62 & 0.46 & 0.48 & 0.04 & $22: 8$ \\
\hline & & & Plot 3 & Terroir & 30 & 29 & 4.87 & 0.47 & 0.49 & 0.03 & $16: 14$ \\
\hline & & & Plot 4 & Terroir & 30 & 27 & 4.75 & 0.45 & 0.47 & -0.02 & $18: 12$ \\
\hline & & & Total or overall & & 120 & 116 & 4.71 & 0.44 & 0.46 & & $71: 49$ \\
\hline & & Total or overall & & & 240 & 231 & 4.61 & 0.44 & 0.46 & 0.01 & $121 / 119$ \\
\hline \multirow[t]{6}{*}{ Plant } & \multirow[t]{6}{*}{2012} & \multirow[t]{6}{*}{ Vieille-Eglise } & Plant 1 & Pireneo & 25 & 25 & 5.37 & 0.58 & 0.61 & 0.07 & $5: 20$ \\
\hline & & & Plant 2 & Pireneo & 18 & 18 & 4.87 & 0.60 & 0.64 & 0.05 & $13: 5$ \\
\hline & & & Plant 3 & Pireneo & 20 & 19 & 4.75 & 0.58 & 0.62 & 0.02 & $9: 10$ \\
\hline & & & Plant 4 & Pireneo & 23 & 20 & 4.50 & 0.53 & 0.55 & 0.01 & $11: 9$ \\
\hline & & & Plant 5 & Pireneo & 19 & 17 & 4.12 & 0.49 & 0.52 & 0.10 & $11: 6$ \\
\hline & & & Total or overall & & 105 & 99 & 4.72 & 0.56 & 0.59 & 0.03 & 49:50 \\
\hline \multirow[t]{5}{*}{ Leaf layer } & \multirow[t]{5}{*}{2012} & \multirow[t]{5}{*}{ Vieille Eglise } & Leaf layer 1 & Pireneo & 34 & 29 & 5.62 & 0.53 & 0.55 & 0.01 & $15: 14$ \\
\hline & & & Leaf layer 2 & Pireneo & 39 & 39 & 5.87 & 0.58 & 0.59 & 0.02 & $17: 22$ \\
\hline & & & Leaf layer 3 & Pireneo & 27 & 26 & 5.62 & 0.60 & 0.63 & 0.05 & $17: 9$ \\
\hline & & & Leaf layer 4 & Pireneo & 5 & 5 & 2.37 & 0.44 & 0.55 & 0.18 & $1: 4$ \\
\hline & & & Total or overall & & 105 & 99 & 4.87 & 0.54 & 058 & 0.03 & $50: 49$ \\
\hline
\end{tabular}

a Number of isolates.

b Number of haplotypes per subpopulation, calculated with XSTAT.

c Number of different alleles averaged over all loci, calculated with GenAlEx version 6.501.

d Nei's gene diversity averaged over all loci, calculated with GenAlEx version 6.501.

e Unbiased gene diversity averaged over all loci, calculated with GenAlEx version 6.501.

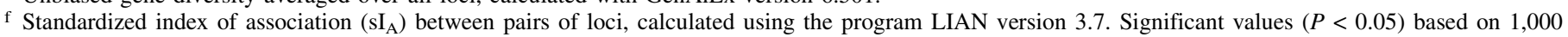
permutations according to Haubold and Hudson (2000) are indicated in bold. Persisting significant values $(P<0.05)$ with the same test, after the removal of isolates with private alleles, are marked by an asterisk.

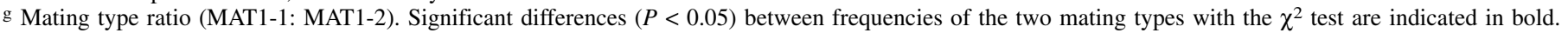

h Mixture with the cultivars Premio, Boisseau, Apache, Oakley, Bermude, and Caphorn.

TABLE 3. Genetic structure at eight microsatellite markers in Zymoseptoria tritici subcollections sampled in northern France (Hauts-de-France region) from different scales

\begin{tabular}{|c|c|c|c|c|c|c|c|c|c|c|c|c|c|c|c|c|}
\hline \multirow[b]{2}{*}{ Locus } & \multirow[b]{2}{*}{$\mathrm{F}_{\mathrm{ST}}^{\mathrm{a}}$} & \multicolumn{3}{|c|}{ Region } & \multirow[b]{2}{*}{$\mathrm{F}_{\mathrm{ST}}$} & \multicolumn{3}{|c|}{ Field } & \multirow[b]{2}{*}{$\mathrm{F}_{\mathrm{ST}}$} & \multicolumn{3}{|c|}{ Plant } & \multirow[b]{2}{*}{$\mathrm{F}_{\mathrm{ST}}$} & \multicolumn{3}{|c|}{ Leaf layer } \\
\hline & & $\mathrm{G}_{\mathrm{ST}}^{\mathrm{b}}$ & $\mathrm{G}^{\prime \prime} \mathrm{ST}^{\mathrm{c}}$ & $D_{e s t}{ }^{\mathrm{d}}$ & & $\mathrm{G}_{\mathrm{ST}}$ & $\mathrm{G}^{\prime \prime}{ }_{\mathrm{ST}}$ & $D_{e s t}$ & & $\mathrm{G}_{\mathrm{ST}}$ & $\mathrm{G}^{\prime \prime}{ }_{\mathrm{ST}}$ & $D_{e s t}$ & & $\mathrm{G}_{\mathrm{ST}}$ & $\mathrm{G}^{\prime \prime}{ }_{\mathrm{ST}}$ & $D_{e s t}$ \\
\hline ST2C10 & $0.63^{\mathrm{e}}$ & 0.62 & 0.85 & 0.60 & 0.03 & 0.01 & 0.01 & 0.00 & 0.05 & 0.01 & 0.03 & 0.01 & 0.02 & 0.00 & 0.00 & 0.00 \\
\hline ST2E4 & 0.48 & 0.45 & 0.82 & 0.66 & 0.04 & 0.01 & 0.01 & 0.00 & 0.05 & 0.01 & 0.02 & 0.01 & 0.02 & 0.00 & 0.02 & 0.01 \\
\hline AC0007 & 0.36 & 0.33 & 0.49 & 0.21 & 0.03 & 0.01 & 0.04 & 0.03 & 0.04 & 0.00 & 0.00 & 0.00 & 0.04 & 0.02 & 0.10 & 0.04 \\
\hline ST1E7 & 0.17 & 0.13 & 0.28 & 0.16 & 0.03 & 0.00 & 0.01 & 0.01 & 0.03 & 0.00 & 0.00 & 0.00 & 0.02 & 0.00 & 0.00 & 0.00 \\
\hline ST1D7 & 0.15 & 0.11 & 0.42 & 0.34 & 0.02 & 0.01 & 0.06 & 0.05 & 0.10 & 0.06 & 0.21 & 0.14 & 0.02 & 0.00 & 0.01 & 0.01 \\
\hline ST1A4 & 0.13 & 0.09 & 0.26 & 0.18 & 0.03 & 0.01 & 0.01 & 0.00 & 0.08 & 0.03 & 0.08 & 0.04 & 0.05 & 0.03 & 0.09 & 0.05 \\
\hline ST1G7 & 0.11 & 0.08 & 0.21 & 0.14 & 0.05 & 0.02 & 0.02 & 0.01 & 0.05 & 0.00 & 0.01 & 0.00 & 0.02 & 0.00 & 0.00 & 0.00 \\
\hline ST1E3 & 0.07 & 0.03 & 0.07 & 0.04 & 0.04 & 0.01 & 0.01 & 0.01 & 0.03 & 0.00 & 0.00 & 0.00 & 0.02 & 0.00 & 0.01 & 0.01 \\
\hline Mean ${ }^{\mathrm{e}}$ & 0.27 & 0.23 & 0.49 & 0.32 & 0.03 & 0.01 & 0.02 & 0.02 & 0.05 & 0.01 & 0.04 & 0.02 & 0.03 & 0.01 & 0.03 & 0.01 \\
\hline
\end{tabular}

a $\mathrm{F}_{\mathrm{ST}}=$ Wright's $\mathrm{F}$ index providing a measure of genetic differentiation among populations, calculated with GenAlEx version 6.501 .

b $\mathrm{G}_{\mathrm{ST}}=$ Nei's fixation index estimating genetic differentiation among subpopulations, calculated with POPGENE version 1.32.

${ }^{c} \mathrm{G}^{\prime \prime}{ }_{\mathrm{ST}}=$ Hedrick's standardized $\mathrm{G}_{\mathrm{ST}}$, adjusted for small population size, calculated with GenAlEx version 6.501 .

d $D_{\text {est }}=$ Jost's $D_{\text {est }}$ standardized fixation index, implemented in GenAlEx version 6.501 .

e Significant values at $P=0.05$, based on 1,000 permutations using GenAlEx version 6.501 software, are highlighted in bold. 
were significant at $P=0.05$, except for location $1 /$ location 2 and location 8/location 9 combinations, which showed nonsignificant genetic differentiation (Table 3). Bayesian analysis implemented in Structure version 2.3.4 supported the occurrence of genetic differentiation among locations and showed that several haplotypes had mixed origins (Fig. 3C). The measures of $\Delta \mathrm{K}$ calculated from $\mathrm{LnP}(\mathrm{D})$ revealed that $\mathrm{K}=6$ is the most likely number of clusters (highest $\Delta \mathrm{K}$ value $=23.10$ ). The six identified clusters were overall differentially distributed among the sampled locations. Cluster 1 (in blue) is relatively more present in locations 1, 2, and 3; clusters 2 and 3 (in yellow and green) in locations 3 and 4; clusters 4 and 6 (in red and clear blue) in locations 5, 6, 8, 9, 10, 11, and 12; and the cluster 5 (in pink) in location 7 and 11 (Fig. 3A).

Interestingly, the dendrogram constructed using the unweighted neighbor-joining method clearly highlighted a clustering of the haplotypes according to their geographical origin (Fig. 4). Most of fungal haplotypes from each location seem to cluster together in a same group, except for location 11 (in black) where individuals were mostly distributed in different groups. Overall, haplotype clustering in the dendrogram was consistent with that highlighted using the Structure program, with several common cluster features (Figs. 3 and 4). Location 7 generated a separate cluster with both approaches. Locations 1, 2, and 3, with a higher proportion of blue in Figure 3, clustered together in Figure 4. Locations 8 and 9, on one hand, and locations 5, 6, and 12, on the other hand, clustered together as shown in Figure 4, while these locations shared similar cluster patterns in Figure 3. Clustering of locations 5 and 6 as well as locations 8 and 9 is supported by the pairwise $F_{\mathrm{ST}}$ and $\Phi_{\mathrm{PT}}$ values, which indicated a nonsignificant genetic subdivision among these location combinations (Table 3). However, locations 4 and 10 clustered closely to each other in Figure 4, although these locations showed distinct clustering profiles in Figure 3.

Directional relative migration network revealed disparate levels of gene flow among locations (Fig. 5). The highest rate of relative migration occurred from location 6 to location $12(0.88)$, while the lowest rate was obtained from location 6 to location $3(0.20)$. Location 4 was the one receiving gene flow to the most extent, which occurred from all locations except locations 3 and 7 . No gene flow was observed toward location 7. Instead, a high level of relative migration occurred from this location to locations 6 and 11. Overall, no clear relationship between the relative directional migration rates and geographic position of the locations across the Hauts-de-France region was observed (Figs. 3 and 4). Data analyses using the Mantel test confirmed this conclusion and revealed a lack of relationship between the amounts of genetic clustering $\left(\Phi_{\mathrm{PT}}\right)$ and the distance (in kilometers) between locations ( $r=0.02, P=0.49>0.05)$, indicating an absence of isolation by distance event within the investigated region.

Z. tritici displays a near random mating and a strong potential for sexual reproduction. Both fungal mating types (MAT1-1 and MAT1-2) were identified in all sampled collections (Table 2). A $\chi^{2}$ test applied to examine deviation from the 1:1 ratio null hypothesis, expected for random-mating populations, revealed nonsignificant difference between the idiomorph frequencies in all studied collections and corresponding subcollections, except in the plant 1 subcollection, where the mating type proportions departed significantly $(P=0.03<0.05)$ from the $1: 1$ ratio (Table 2$)$. The two mating types were detected on all of the five plants and the four leaf layers studied, and found to co-occur together on the same leaf on 13 $(81 \%)$ of the 16 wheat leaves from which at least two isolates were sampled (Fig. 1). The values of the multilocus standardized index of association $\left(\mathrm{sI}_{\mathrm{A}}\right)$ were overall very low and indicated no departure from gametic equilibrium in most of the sampled subcollections, except for plants 1 and 2, and leaf layers 3 and 4 subcollections (Table 2). Low but significant values of $\mathrm{sI}_{\mathrm{A}}$ were also obtained at the whole collection level, at region, plant, and leaf layer scales. Additional analyses performed without haplotypes with private alleles resulted in nonsignificant values of $\mathrm{sI}_{\mathrm{A}}$ in the collections and subcollections from both plant and leaf layer scales (data not shown). Extreme allele frequencies are known to provide misleading measures of

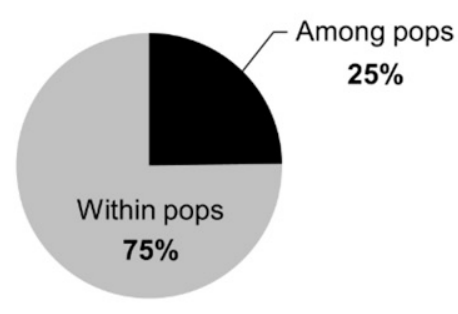

Region

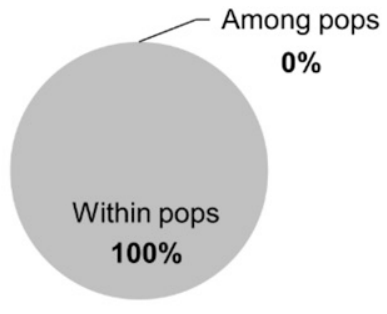

Field

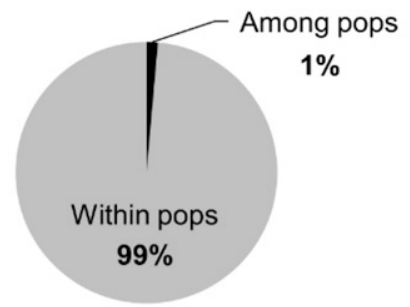

Plant

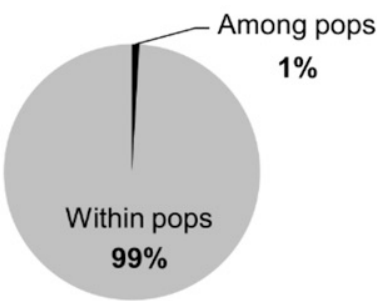

Leaf layer

Fig. 2. Hierarchic analysis of molecular variance in Zymoseptoria tritici subcollections sampled in northern France (Hauts-de-France region) from different scales. Percentage of molecular variance is indicated in gray within collections (pops) and in black among collections.

TABLE 4. Population differentiation measured by $\mathrm{F}_{\mathrm{ST}}$ (below the diagonal) and PhiPT $\left(\Phi_{\mathrm{PT}}\right.$ ) (above the diagonal) among 12 Zymoseptoria tritici subcollections sampled in northern France (Hauts-de-France region) from different locations ${ }^{\mathrm{a}}$

\begin{tabular}{lcccccccccccc}
\hline Location & L1 & L2 & L3 & L4 & L5 & L6 & L7 & L8 & L9 & L10 & L11 & L12 \\
\hline L1 & $\ldots$ & 0.02 & $\mathbf{0 . 1 6}$ & $\mathbf{0 . 2 5}$ & $\mathbf{0 . 2 3}$ & $\mathbf{0 . 2 8}$ & $\mathbf{0 . 2 2}$ & $\mathbf{0 . 2 7}$ & $\mathbf{0 . 2 8}$ & $\mathbf{0 . 2 0}$ & $\mathbf{0 . 1 4}$ & $\mathbf{0 . 2 9}$ \\
L2 & 0.03 & $\ldots$ & $\mathbf{0 . 0 9}$ & $\mathbf{0 . 2 4}$ & $\mathbf{0 . 2 6}$ & $\mathbf{0 . 3 0}$ & $\mathbf{0 . 2 1}$ & $\mathbf{0 . 2 4}$ & $\mathbf{0 . 2 3}$ & $\mathbf{0 . 2 1}$ & $\mathbf{0 . 1 3}$ & $\mathbf{0 . 2 6}$ \\
L3 & $\mathbf{0 . 1 1}$ & $\mathbf{0 . 0 7}$ & $\ldots$ & $\mathbf{0 . 2 1}$ & $\mathbf{0 . 2 9}$ & $\mathbf{0 . 3 4}$ & $\mathbf{0 . 2 5}$ & $\mathbf{0 . 2 8}$ & $\mathbf{0 . 2 7}$ & $\mathbf{0 . 2 5}$ & $\mathbf{0 . 1 4}$ & $\mathbf{0 . 2 3}$ \\
L4 & $\mathbf{0 . 1 6}$ & $\mathbf{0 . 1 6}$ & $\mathbf{0 . 1 4}$ & $\ldots$ & $\mathbf{0 . 2 7}$ & $\mathbf{0 . 3 2}$ & $\mathbf{0 . 2 6}$ & $\mathbf{0 . 3 2}$ & $\mathbf{0 . 3 2}$ & $\mathbf{0 . 2 6}$ & $\mathbf{0 . 2 0}$ & $\mathbf{0 . 2 7}$ \\
L5 & $\mathbf{0 . 1 5}$ & $\mathbf{0 . 1 7}$ & $\mathbf{0 . 1 9}$ & $\mathbf{0 . 1 8}$ & $\ldots$ & $\mathbf{0 . 0 9}$ & $\mathbf{0 . 2 7}$ & $\mathbf{0 . 3 7}$ & $\mathbf{0 . 3 8}$ & $\mathbf{0 . 2 5}$ & $\mathbf{0 . 1 6}$ & $\mathbf{0 . 3 1}$ \\
L6 & $\mathbf{0 . 1 9}$ & $\mathbf{0 . 2 0}$ & $\mathbf{0 . 2 3}$ & $\mathbf{0 . 2 1}$ & $\mathbf{0 . 0 7}$ & $\ldots$ & $\mathbf{0 . 3 1}$ & $\mathbf{0 . 3 7}$ & $\mathbf{0 . 3 7}$ & $\mathbf{0 . 3 3}$ & $\mathbf{0 . 1 8}$ & $\mathbf{0 . 2 5}$ \\
L7 & $\mathbf{0 . 1 5}$ & $\mathbf{0 . 1 4}$ & $\mathbf{0 . 1 7}$ & $\mathbf{0 . 1 7}$ & $\mathbf{0 . 1 7}$ & $\mathbf{0 . 2 0}$ & $\ldots$ & $\mathbf{0 . 3 4}$ & $\mathbf{0 . 3 3}$ & $\mathbf{0 . 3 1}$ & $\mathbf{0 . 1 6}$ & $\mathbf{0 . 3 5}$ \\
L8 & $\mathbf{0 . 1 8}$ & $\mathbf{0 . 1 6}$ & $\mathbf{0 . 1 9}$ & $\mathbf{0 . 2 1}$ & $\mathbf{0 . 2 5}$ & $\mathbf{0 . 2 5}$ & $\mathbf{0 . 2 3}$ & $\ldots$ & 0.03 & $\mathbf{0 . 2 5}$ & $\mathbf{0 . 1 8}$ & $\mathbf{0 . 2 5}$ \\
L9 & $\mathbf{0 . 1 8}$ & $\mathbf{0 . 1 5}$ & $\mathbf{0 . 1 8}$ & $\mathbf{0 . 2 2}$ & $\mathbf{0 . 2 6}$ & $\mathbf{0 . 2 5}$ & $\mathbf{0 . 2 2}$ & 0.04 & $\ldots$ & $\mathbf{0 . 2 5}$ & $\mathbf{0 . 1 9}$ & $\mathbf{0 . 2 9}$ \\
L10 & $\mathbf{0 . 1 3}$ & $\mathbf{0 . 1 4}$ & $\mathbf{0 . 1 6}$ & $\mathbf{0 . 1 7}$ & $\mathbf{0 . 1 7}$ & $\mathbf{0 . 2 2}$ & $\mathbf{0 . 2 1}$ & $\mathbf{0 . 1 7}$ & $\mathbf{0 . 1 7}$ & $\ldots$ & $\mathbf{0 . 1 0}$ & $\mathbf{0 . 2 3}$ \\
L11 & $\mathbf{0 . 1 0}$ & $\mathbf{0 . 0 9}$ & $\mathbf{0 . 1 0}$ & $\mathbf{0 . 1 4}$ & $\mathbf{0 . 1 1}$ & $\mathbf{0 . 1 2}$ & $\mathbf{0 . 1 1}$ & $\mathbf{0 . 1 3}$ & $\mathbf{0 . 1 3}$ & $\mathbf{0 . 0 7}$ & $\ldots$ & $\mathbf{0 . 1 1}$ \\
L12 & $\mathbf{0 . 1 9}$ & $\mathbf{0 . 1 7}$ & $\mathbf{0 . 1 5}$ & $\mathbf{0 . 1 8}$ & $\mathbf{0 . 2 0}$ & $\mathbf{0 . 1 7}$ & $\mathbf{0 . 2 3}$ & $\mathbf{0 . 1 7}$ & $\mathbf{0 . 2 0}$ & $\mathbf{0 . 1 5}$ & $\mathbf{0 . 0 8}$ & $\ldots$ \\
\hline
\end{tabular}

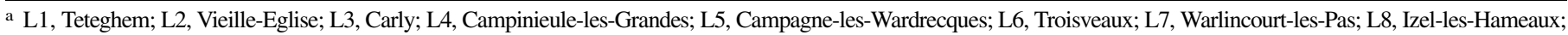
L9, Carvin; L10, Bapaume; L11, Marcq-en-Ostrevent; and L12, Sautain. Significant values at $P=0.01$, based on 1,000 permutations using GenAlEx version 6.501 software, are highlighted in bold. 
gametic disequilibrium (Asmussen and Basten 1994). However, the weak gametic disequilibrium observed in the whole region collection remained significant even when the haplotypes with private alleles were excluded from the analysis, likely because of larger sample size and lower frequency of private alleles in this collection (data not shown).

\section{DISCUSSION}

High levels of genetic diversity were scored for Z. tritici in northern France (Hauts-de-France region) at all investigated scales. Interestingly, we found similar patterns of both gene and genotype diversities in the biggest (region), the intermediate (field), and smallest (plant) spatial scales. High levels of genetic diversity were previously recorded in larger (country) or similar (region, field) geographical scales (Boukef et al. 2012; Drabešová et al. 2013; El
Chartouni et al. 2011; Gurung et al. 2011; Kabbage et al. 2009; Linde et al. 2002; Welch et al. 2017; Zhan et al. 2003). Nonetheless, lower, but still consequent, levels of genetic diversity were detected in very fine niches such as a single leaf and even a single lesion (El Chartouni et al. 2012; Linde et al. 2002). Our results complete these findings and report for the first time very high degree of genetic diversity for $Z$. tritici on a single plant. Taken together, these findings indicate that $Z$. tritici have substantial, and overall similar patterns, of both gene and genotype diversities at global, regional, field, and even at the single plant scale, as revealed in this study. The diversity then decreased at a single leaf and a single lesion, as a result of very locally confined asexual multiplication within clonal pycnidiospores.

To our knowledge, our work is the first study assessing fungal genetic diversity at a single cereal plant level by considering the different plant leaf layers. Surprisingly, we identified only five pairs
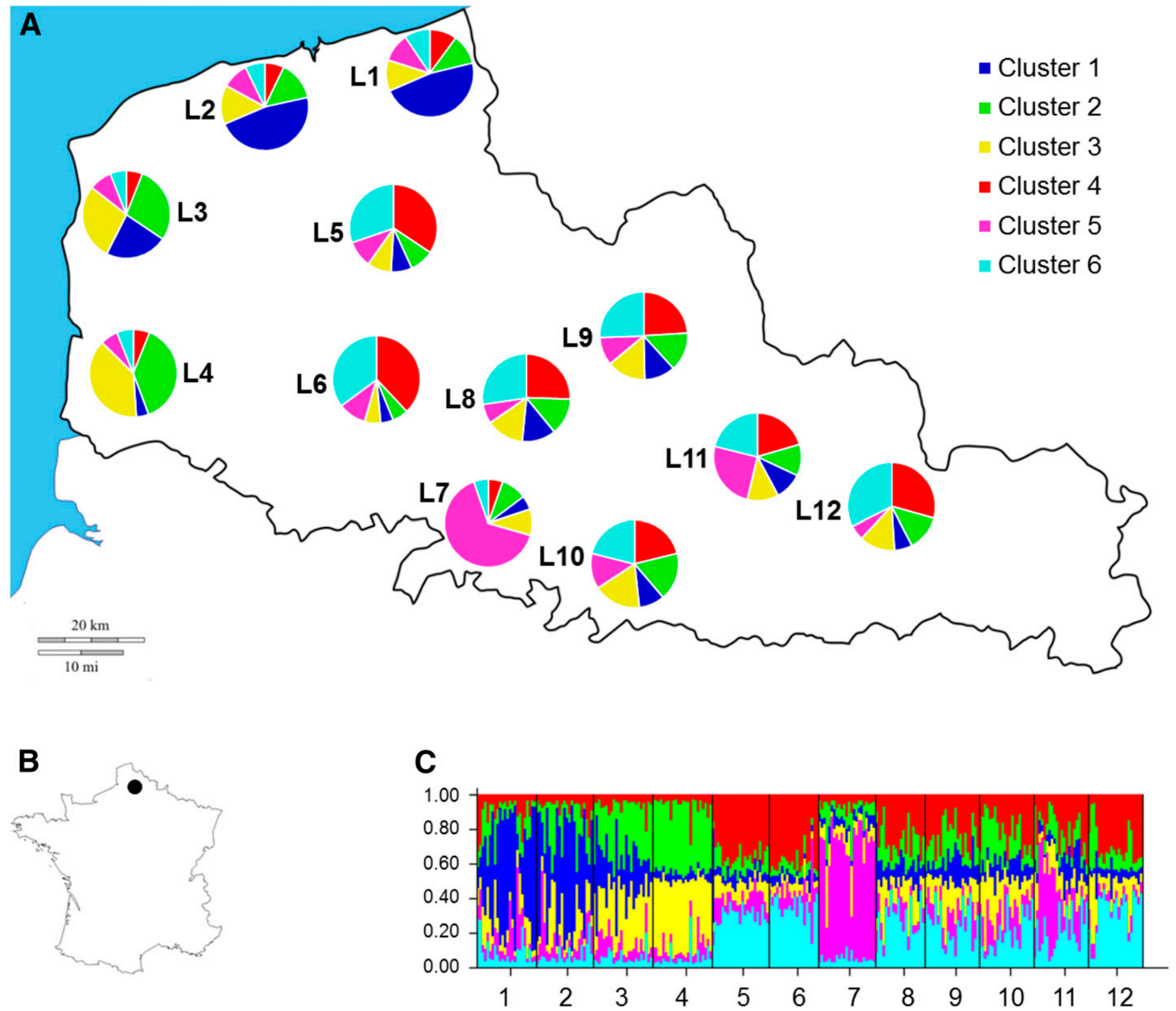

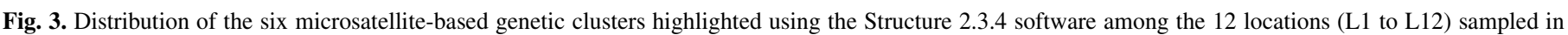

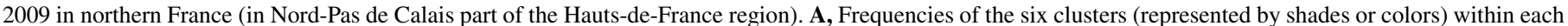

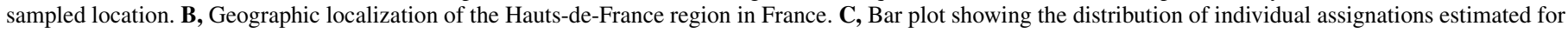

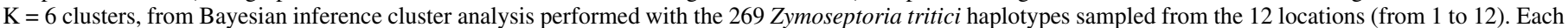

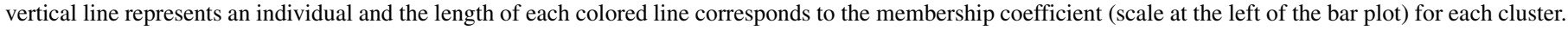

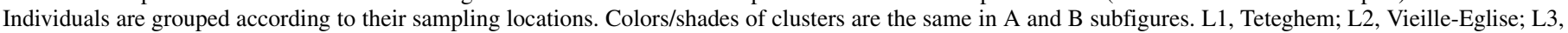

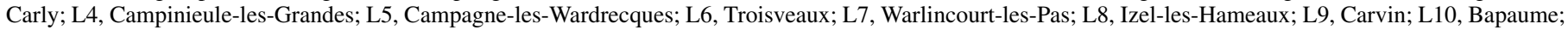
L11, Marcq-en-Ostrevent; and L12, Sautain. 
of clones originating from the same leaf but from different lesions, although significant numbers of both isolates (more than 100) and leaves (16 leaves with more than one isolate, with an average of 6.5 isolates per leaf, all taken from different lesions) were examined. This finding demonstrates that, at least in our conditions, lesions with common haplotypes are rare in wheat leaves infected by Z. tritici, and suggests that the different lesions observed in the field on a same leaf are mainly caused by pycnidiospores or ascospores originated from other leaves. On the other hand, we scored only two pairs of clones which occurred on different leaf layers; two clones on a same plant and two other clones on two different plants (Fig. 1). Such a rare occurrence of identical haplotypes on different leaf layers of the same plant or plants from the same microsurface is surprising and unpredicted, since $Z$. tritci is known to be dispersed locally extensively with clonal pycnidiospores, through rain splashing and physical contact between infected and healthy leaves (Eyal 1999). Significant contribution of windborn ascospores to the fungal epidemics has been suggested since the release of such spores all over the year was detected using spore-trapping or isolation experiments (Duvivier et al. 2013; Hunter et al. 1999; Suffert and Sache 2011). Our results support these findings and show that ascospores contribute much more than expected to $Z$. tritci epidemics, and therefore, should be considered not only as a primary source of inoculum, but also as a significant source of secondary inoculum strongly involved in wheat plant infection and disease progression. Interestingly, most of the clones we detected within the leaf layer collection occurred on leaf layer 1 (four clones), with an occurrence of three clones on two different leaves (Fig. 1). Despite the relatively small sample of isolates studied, such result could be a signature of more active asexual multiplication and pycnidiospore dispersal in upper leaves than in lower leaves within the canopy. Nevertheless, the relative importance of each type of spores (pycnidiospores versus ascospores) in the epidemiology of the pathogen deserves to be further deciphered using in-depth dedicated experiments.

As expected, our analyses showed no genetic structuration for $Z$. tritici at small scales such as single field or single plant. An absence of genetic differentiation for Z tritici at the field level (in experimental plots) has already been observed by using nonBayesian statistical analyses (Linde et al. 2002). Our investigation performed using a large sample size (240 isolates), and using both non-Bayesian and Bayesian (i.e., analyzing genetic clustering in $Z$. tritici at the field scale. Likewise, we found nonsignificant fungal genetic differentiation at both plant and leaf layer scales. Such fine and local spatial scales, including the field one, are unlikely to be sites of genetic structuration, especially in pathogens with windborn spores. Frequent production of ascospores by the pathogen during the sexual stage certainly leads to permanent gene flow and allele pool homogenization in the field. Our detection of the two fungal mating types at equal frequencies at all assessed scales agrees with this hypothesis and point out regular cycles of sexual reproduction for $Z$. tritici in the Hauts-de-France Region, thus corroborating previous reports (Siah et al. 2010; Zhan et al. 2002). The frequent co-occurrence of the two idiomorphs we highlighted on the same leaf ( $81 \%$ of analyzed leaves) offers to the pathogen the opportunity for sexual contact, and then subsequent mating. Recurrent sexual recombination is likely the main process responsible for the strong genetic diversity observed in Z. tritici (El Chartouni et al. 2011; Siah et al. 2010; Zhan et al. 2003).

Interestingly, we observed a significant genetic structure at the region level among the different locations, as revealed by all calculated fixation indices as well as AMOVA (Table 3; Fig. 2), indicating that populations of $Z$. tritici in the Hauts-de-France Region are not part of a single panmictic population. Our work is the first report of significant population differentiation for $Z$. tritici at a relatively reduced spatial area $\left(12,414 \mathrm{~km}^{2}\right)$. Significant levels of genetic structure have recently been reported at largest scales among Z. tritici collections from different countries (Boukef et al. 2012; Drabešová et al. 2013; Grandaubert et al. 2017), or among subcollections from a single country (Abrinbana et al. 2010; El Chartouni et al. 2011; Gurung et al. 2011). In Iran for instance, a strong genetic differentiation $\left(\mathrm{G}_{\mathrm{ST}}=0.39\right)$ was scored among five

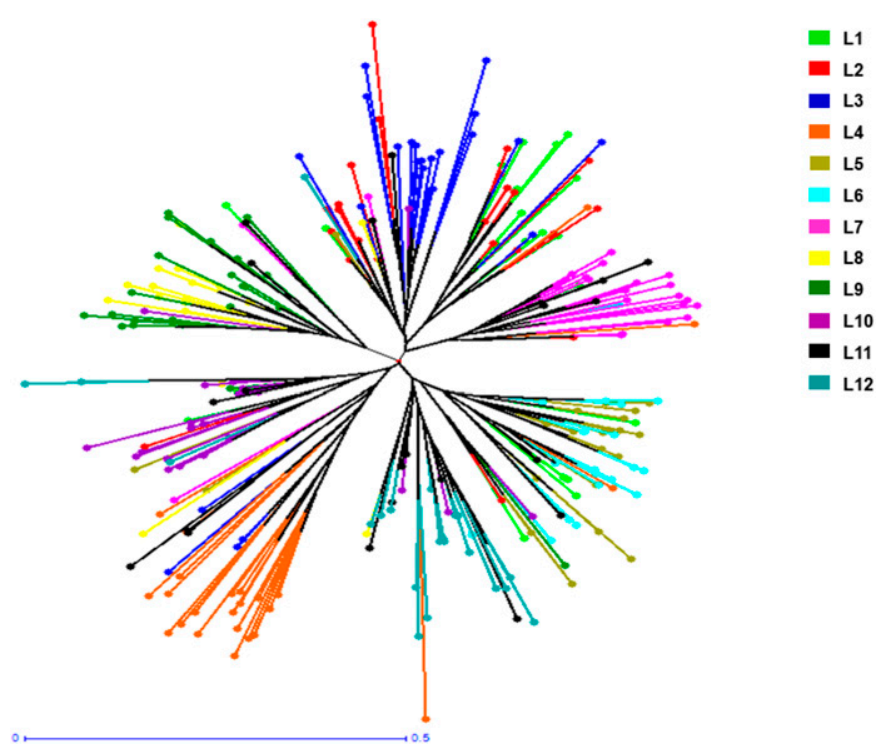

Fig. 4. Dendrogram showing genetic clustering of 269 Zymoseptoria tritici haplotypes sampled from 12 geographic locations (from L1 to L12) in northern France (Hauts-de-France region). The tree was constructed using the unweighted neighbor-joining method based on genetic dissimilarity among the haplotypes according to microsatellite markers. Each branch corresponds to a Z. tritici genotype and the colors of branches indicate locations from which the genotypes were sampled. L1, Teteghem; L2, Vieille-Eglise; L3, Carly; L4, Campinieule-les-Grandes; L5, Campagne-les-Wardrecques; L6, Troisveaux; L7, Warlincourt-les-Pas; L8, Izel-les-Hameaux; L9, Carvin; L10, Bapaume; L11, Marcq-en-Ostrevent; and L12, Sautain.

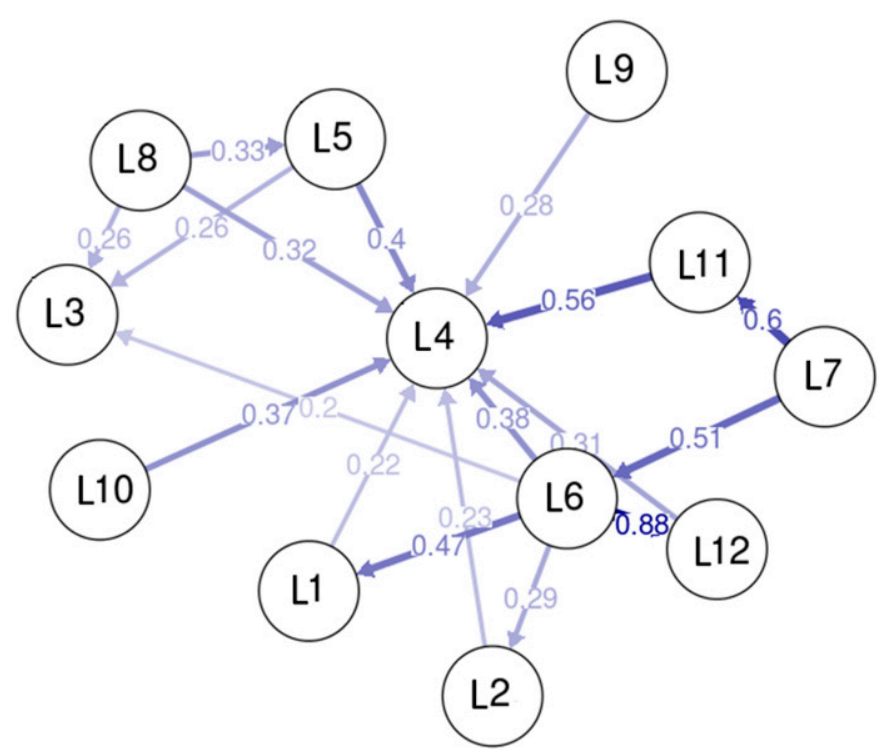

Fig. 5. Directional relative migration network among 12 Zymoseptoria tritici locations (L1 to L12) sampled in northern France (Hauts-de-France region). Arrows indicate the direction of gene flow based on Jost's $D$ as measure and with a bootstrap value of 1,000 performed on divMigrate program. Arrow length, shading, and thickness are determined by the relative strength of gene flow. Numbers show the values of directional migration relative to the highest value (0.88) highlighted in the analysis (from L6 to L12). L1, Teteghem; L2, Vieille-Eglise; L3, Carly; L4, Campinieule-les-Grandes; L5, Campagne-lesWardrecques; L6, Troisveaux; L7, Warlincourt-les-Pas; L8, Izel-les-Hameaux; L9, Carvin; L10, Bapaume; L11, Marcq-en-Ostrevent; and L12, Sautain. 
major wheat-growing provinces, including two provinces only $\sim 100 \mathrm{~km}$ apart from each other (Abrinbana et al. 2010), therefore agreeing with our results. Most of the observed genetic differentiation in Z. tritici populations has been suggested to be due to genetic drift, geographic barriers and local adaptation of the fungus to different climates, wheat cultivars, crop rotation patterns and cultural practices (Abrinbana et al. 2010; El Chartouni et al. 2011; Grandaubert et al. 2017; Gurung et al. 2011). Nevertheless, several earlier studies carried out using RFLP markers reported no or little genetic structure in Z. tritici populations at local, regional, as well as global scales, due to long distance gene flow (Linde et al. 2002; Zhan et al. 2003). Overall, the genetic structure of $Z$. tritici within the different studied populations varies depending on the sampled area and/or the type of marker used. For instance, microsatellites are highly polymorphic and have overall a faster rate of evolution compared with other markers such as RFLP. Therefore, microsatellites are expected to be more sensitive to recent phylogeographic and demographic events, making them as one of the choice markers for population genetic analyses (Linde et al. 2010).

Additional analyses using both Bayesian and unweighted neighbor-joining methods detected six genetically differentiated clusters in the Hauts-de-France $Z$. tritici collection, occurring overall according to the geographical locations from which the isolates were sampled (Figs. 3 and 4). A clustering of the whole French population of $Z$. tritici into three genetic groups, explained by a potential adaptation of the fungus to local conditions, has previously been obtained at the country scale (El Chartouni et al. 2011). In our case, the reasons leading to the structuration of the regional collection were not elucidated since no clear main direction of gene flow among the sampled locations (according to the direction from west to east prevailing winds for instance) (Figs. 3 and 5), and no significant isolation by distance $(P=0.49>0.05)$, were observed. The forces causing the differentiation are thus not known. Genetic drift is unlikely because the pathogen populations possess very large effective sizes, especially in the studied region, where Z. tritici pressure is strong and frequent. By contrast, selection at one or more of the targeted (or closely linked) microsatellite loci can be a plausible hypothesis to explain the observed clustering, as well as the slight gametic disequilibrium noticed in the whole collection, although this later could also be caused by linkage among loci or physical admixture of samples that differ in allele frequencies. The hypothesis that the structuration is caused by selection and adaptation to habitat heterogeneity could be supported by a recent study, which showed that $44 \%$ of substitutions in the proteome of $Z$. tritici are adaptive, and that the rate of adaptation is positively correlated with recombination rate (Grandaubert et al. 2017). The most likely mechanisms that can drive selection is our case are adaptations to temperature, wind intensity, relative humidity, and/or frost degree since variations in the amplitude and magnitude of such factors can occur among several sampled locations (e.g., locations situated on the Channel coast versus those located inland) (Fig. 3). The involvements of temperature in shortterm selection (over the cropping season) and in the evolution of Z. tritici populations were recently reported (Chen et al. 2017; Suffert et al. 2015). Moreover, it was demonstrated that local temperature interacts with host resistance in influencing the evolution of $Z$. tritici, leading to the conclusion that the evolution of the pathogen in resistant cultivars is less influenced by the environment than in susceptible cultivars (Chen et al. 2017). Therefore, a potential effect of wheat cultivars on our observed structuration cannot be excluded since some locations with a proper cultivar (e.g., location 7, Table 2) diverged genetically from the other locations (Fig. 4). Nonetheless, such factor can explain only partially the structuration since some locations with a same cultivar (e.g., locations 4, 5, and 10, Table 2) showed distinct genetic patterns (Figs. 3 and 4). Another hypothesis to explain the observed clustering is the effect of rainfall that can limit the dispersion of ascospores across the region, since the studied region is characterized by a strong rainfall frequency during the growing season. However, it is likely that the obtained differentiation could be the result of the effect of multiple abiotic and/or biotic factors. Further assays by comparing for instance fitness traits of isolates representative of the six detected clusters could allow identifying the processes responsible for the observed structuration.

Our study gives new insights into the genetic structure of $Z$. tritici. Our findings indicate that $Z$. tritici is a highly diverse even at a single plant level, sexually active and demographically dynamic fungus. With an obtained average of $\sim 20(97 / 5)$ haplotypes/plant, and considering an average density of $250 \mathrm{plants} / \mathrm{m}^{2}$, we can estimate to, at least, 5,000 haplotypes per square meter, i.e., 50 million different Z. tritici genotypes that can occur per hectare, in conditions of strong disease pressure. We can state that such a large effective population size, coupled with the substantial highlighted allele diversity, ranks $Z$. tritici among the most diverse agronomically and economically important plant pathogens. We also revealed that the population of $Z$. tritici in northern France is not part of a single panmictic population, but instead, it is structured into different geographically distributed groups. The reasons of this structuration were not elucidated with our complementary analyses; further investigations are thus required to identify the factors responsible for such differentiation.

\section{LITERATURE CITED}

Abrinbana, M., Mozafiri, J., Shams-bakhsh, M., and Mehrabi, R. 2010. Genetic structure of Mycosphaerella graminicola populations in Iran. Plant Pathol. 59:829-838.

Anon, A. 1996. The Evaluation of Forensic DNA Evidence. National Academy Press, Washington, DC.

Asmussen, M. A., and Basten, J. C. 1994. Sampling theory for cyto-nuclear disequilibria. Genetics 138:1351-1363.

Banke, S., and McDonald, B. A. 2005. Migration patterns among global populations of the pathogenic fungus Mycosphaerella graminicola. Mol. Ecol. 14:1881-1896.

Boukef, S., McDonald, B. A., Yahyaoui, A., Rezgui, S., and Brunner, P. C. 2012. Frequency of mutations associated with fungicide resistance and population structure of Mycosphaerella graminicola in Tunisia. Eur. J. Plant Pathol. 132:111-122.

Chen, F., Duan, G.-H., Li, D. L., and Zhan, J. 2017. Host resistance and temperature-dependent evolution of aggressiveness in the plant pathogen Zymoseptoria tritici. Front. Microbiol. 8:1217.

Cheval, P., Siah, A., Bomble, M., Popper, A. D., Reignault, Ph., and Halama, P. 2017. Evolution of QoI resistance of the wheat pathogen Zymoseptoria tritici in Northern France. Crop Prot. 92:131-133.

Czembor, P. C., and Arseniuk, E. 1999. Study of variability among monopycnidial mononpycnidiospore isolates derived from single pycnidia of Stagonospora ssp. and Septoria tritici with the use of RAPD-PCR, MP-PCR and rep-PCR techniques. J. Phytopathol. 147:539-546.

Dean, R., Van Kan, J. A., Pretorius, Z. A., Hammond-Kosack, K. E., Di Pietro, A., Spanu, P. D., Rudd, J. J., Dickman, M., Kahmann, R., Ellis, J., and Foster, G. D. 2012. The top 10 fungal pathogens in molecular plant pathology. Mol. Plant Pathol. 13:414-430.

Drabešová, J., Ryšánek, P., Brunner, P., McDonald, B. A., and Croll, D. 2013. Population genetic structure of Mycosphaerella graminicola and quinone outside inhibitor (QoI) resistance in the Czech Republic. Eur. J. Plant Pathol. 135:211-224.

Duvivier, M., Dedeurwaerder, G., De Proft, M., Moreau, J. M., and Legrève, A. 2013. Real-time PCR quantification and spatio-temporal distribution of airborne inoculum of Mycosphaerella graminicola in Belgium. Eur. J. Plant Pathol. 137:325-341.

Earl, D. A., and vonHoldt, B. M. 2012. STRUCTURE HARVESTER: A website and program for visualizing STRUCTURE output and implementing the Evanno method. Conserv. Genet. Resour. 4:359-361.

El Chartouni, L., Tisserant, B., Siah, A., Duyme, F., Durand, R., Halama, P., and Reignault, Ph. 2012. Evolution of Mycosphaerella graminicola at the wheat leaf and field levels. Phytopathol. Mediterr. 51:332-339.

El Chartouni, L., Tisserant, B., Siah, A., Duyme, F., Leducq, J. B., Deweer, C., Fichter-Roisin, C., Sanssené, J., Durand, R., Halama, P., and Reignault, P. 2011. Genetic diversity and population structure in French populations of Mycosphaerella graminicola. Mycologia 103:764-774.

Evanno, G., Regnaut, S., and Goudet, J. 2005. Detecting the number of clusters of individuals using the software STRUCTURE: A simulation study. Mol. Ecol. 14:2611-2620. 
Excoffier, L., and Lischer, H. E. L. 2010. Arlequin suite ver 3.5: A new series of programs to perform population genetics analyses under Linux and Windows. Mol. Ecol. Resour. 10:564-567.

Eyal, Z. 1999. The Septoria tritici and Stagonospora nodorum blotch diseases of wheat. Eur. J. Plant Pathol. 105:629-641.

Falush, D., Stephens, M., and Pritchard, J. K. 2003. Inference of population structure: Extensions to linked loci and correlated allele frequencies. Genetics 164:1567-1587.

Goodwin, S. B., Ben M'Barek, S., Dhillon, B., Wittenberg, A. H. J., Crane, C. F., Hane, J. K., Foster, A. J., Van der Lee, T. A. J., Grimwood, J., Aerts, A., Antoniw, J., Bailey, A., Bluhm, B., Bowler, J., Bristow, J., van der Burgt, A., Canto-Canche, B., Churchill, A. C. L., Conde-Ferràez, L., Cools, H. J., Coutinho, P. M., Csukai, M., Dehal, P., De Wit, P., Donzelli, B., van de Geest, H. C., van Ham, R. C. H. J., Hammond-Kosack, K. E., Henrissat, B., Kilian, A., Kobayashi, A. K., Koopmann, E., Kourmpetis, Y., Kuzniar, A., Lindquist, E., Lombard, V., Maliepaard, C., Martins, N., Mehrabi, R., Nap, J. P. H., Ponomarenko, A., Rudd, J. J., Salamov, A., Schmutz, J., Schouten, H. J., Shapiro, H., Stergiopoulos, I., Torriani, S. F. F., Tu, H., de Vries, R. P., Waalwijk, C., Ware, S. B., Wiebenga, A., Zwiers, L.-H., Oliver, R. P., Grigoriev, I. V., and Kema, G. H. J. 2011. Finished genome of the fungal wheat pathogen Mycosphaerella graminicola reveals dispensome structure, chromosome plasticity and stealth pathogenesis. PLoS Genet. 7: e 1002070 .

Goodwin, S. B., van der Lee, T. A., Cavaletto, J. R., Te Lintel Hekkert, B., Crane, C. F., and Kema, J. G. H. 2007. Identification and genetic mapping of highly polymorphic microsatellite loci from an EST database of the Septoria tritici blotch pathogen Mycosphaerella graminicola. Fungal Genet. Biol. 44:398-414.

Grandaubert, J., Dutheil, J. Y., and Stukenbrock, E. H. 2017. The genomic rate of adaptation in the fungal wheat pathogen Zymoseptoria tritici. bioRxiv 176727.

Gurung, S., Goodwin, S. B., Kabbage, M., Bockus, W. W., and Adhikari, T. B. 2011. Genetic differentiation at microsatellite loci among populations of Mycosphaerella graminicola from California, Indiana, Kansas, and North Dakota. Phytopathology 101:1251-1259.

Haubold, H., and Hudson, R. R. 2000. LIAN 3.0: Detecting linkage disequilibrium in multilocus data. Bioinformatics 16:847-848.

Hunter, R., Coker, R. R., and Royle, D. J. 1999. The teleomorph stage, Mycosphaerella graminicola, in epidemics of Septoria tritici blotch on winter wheat in UK. Plant Pathol. 48:51-57.

Jost, L. 2008. $\mathrm{G}_{\mathrm{ST}}$ and its relatives do not measure differentiation. Mol. Ecol. 17:4015-4026.

Kabbage, M., Leslie, J. F., Hulbert, S. H., and Bockus, W. W. 2009. Comparison of natural populations of Mycosphaerella graminicola from single fields in Kansas and California. Physiol. Mol. Plant Pathol. 74:55-59.

Kema, G. H. J., van der Lee, T. A., Mendes, O., Verstappen, E. C., Lankhorst, R. K., Sandbrink, H., van der Burgt, A., Zwiers, L. H., Csukai, M., and Waalwijk, C. 2008. Large-scale gene discovery in the Septoria tritici blotch fungus Mycosphaerella graminicola with a focus on in planta expression. Mol. Plant-Microbe Interact. 21:1249-1260.

Kema, G. H. J., Verstappen, E. C. P., Todorova, M., and Waalwijk, C. 1996. Successful crosses and molecular tetrad and progeny analyses demonstrate heterothallism in Mycosphaerella graminicola. Curr. Genet. 30:251-258.

Linde, C. 2010. Population genetic analyses of plant pathogens: New challenges and opportunities. Australas. Plant Pathol. 39:23-28.

Linde, C., Zhan, J., and McDonald, B. A. 2002. Population structure of Mycosphaerella graminicola: From lesions to continents. Phytopathology 92:946-955.

McDonald, B. A., and Linde, C. 2002. Pathogen population genetics, evolutionary potential, and durable resistance. Annu. Rev. Phytopathol. 40: 349-379.

McDonald, B. A., and Mundt, C. C. 2016. How knowledge of pathogen population biology informs management of Septoria tritici blotch. Phytopathology 106:948-955.

Meirmans, P. G. 2006. Using the AMOVA framework to estimate a standardized genetic differentiation measure. Evolution 60:2399-2402.

Meirmans, P. G., and Hedrick, P. W. 2011. Assessing population structure: $F_{\text {ST }}$ and related measures. Mol. Ecol. Resour. 11:5-18.
Milgroom, M. G. 2015. Population Biology of Plant Pathogens: Genetics, Ecology and Evolution. American Phytopathological Society Press, St. Paul, MN.

Nei, M. 1973. Analysis of gene diversity in subdivided populations. Proc. Natl. Acad. Sci. USA 70:3321-3323.

O'Driscoll, A., Kildea, S., Doohan, F., Spink, J., and Mullins, E. 2014. The wheat-Septoria conflict: A new front opening up? Trends Plant Sci. 19: 602-610

Owen, P. G., Pei, M., Karp, A., Royle, D. J., and Edwards, K. J. 1998. Isolation and characterization of microsatellite loci in the wheat pathogen Mycosphaerella graminicola. Mol. Ecol. 7:1611-1612.

Peakall, R., and Smouse, P. E. 2012. GenAlEx 6.5: Genetic analysis in Excel. Population genetic software for teaching and research - An update. Bioinformatics 28:2537-2539.

Perrier, X., and Jacquemoud-Collet, J. P. 2006. DARwin software. http://darwin. cirad.fr

Pritchard, J. K., Stephens, M., and Donnelly, P. 2000. Inference of population structure using multilocus genotype data. Genetics 155:945-959.

Siah, A., Elbekali, A. Y., Ramdani, A., Reignault, P., Torriani, S. F. F., Brunner, P. C., and Halama, P. 2014. QoI resistance and mitochondrial genetic structure of Zymoseptoria tritici in Morocco. Plant Dis. 98: 1138-1144

Siah, A., Tisserant, B., El Chartouni, L., Duyme, F., Deweer, C., Fichter, C., Sanssené, J., Durand, R., Reignault, Ph., and Halama, P. 2010. Mating type idiomorphs from a French population of the wheat pathogen Mycosphaerella graminicola: Widespread equal distribution and low but distinct levels of molecular polymorphism. Fungal Biol. 114:980-990.

Stukenbrock, E. H., and McDonald, B. A. 2008. The origins of plant pathogens in agro-ecosystems. Annu. Rev. Phytopathol. 46:75-100.

Suffert, F., Ravigné, V., and Sache, I. 2015. Seasonal changes drive short-term selection for fitness traits in the wheat pathogen Zymoseptoria tritici. Appl. Environ. Microbiol. 81:6367-6379.

Suffert, F., and Sache, I. 2011. Relative importance of different types 679 of inoculum to the establishment of Mycosphaerella graminicola in wheat crops in north-west Europe. Plant Pathol. 60:878-889.

Sundqvist, L., Keenan, K., Zackrisson, M., Prodöhl, P., and Kleinhans, D. 2016. Directional genetic differentiation and relative migration. Ecol. Evol. 6:3461-3475.

Torriani, S. F. F., Brunner, P. C., and McDonald, B. A. 2011. Evolutionary history of the mitochondrial genome in Mycosphaerella populations infecting bread wheat, durum wheat and wild grasses. . Mol. Phylogenet. Evol. 58: 192-197.

Waalwijk, C., Mendes, O., Verstappen, E. C. P., Waard, M. A., and Kema, G. H. J. 2002. Isolation and characterisation of the mating type idiomorphs from the wheat Septoria leaf blotch fungus Mycosphaerella graminicola. Fungal Genet. Biol. 35:277-286.

Welch, T., Feechan, A., and Kildea, S. 2017. Effect of host resistance on genetic structure of core and accessory chromosomes in Irish Zymoseptoria tritici. Eur. J. Plant Pathol. 150:139-148.

Whitlock, M. C. 2011. $\mathrm{G}_{\text {ST }}^{\prime}$ and D do not replace F $\mathrm{F}_{\text {ST }}$ Mol. Ecol. 20: 1083-1091.

Yeh, F. C., Yang, R., and Boyle, T. 2000. Popgene 1.32. The user-friendly software for population genetic analysis. Molecular Biology and Biotechnology Center, University of Alberta, and CIFOR, Canada. https://sites. ualberta.ca/ fyeh/index.html

Zhan, J., Kema, G. H. J., Waalwijk, C., and McDonald, B. A. 2002. Distribution of mating type alleles in the wheat pathogen Mycosphaerella graminicola over special scales from lesions to continents. Fungal Genet. Biol. 36:128-136.

Zhan, J., Pettway, R. E., and McDonald, B. A. 2003. The global genetic structure of the wheat pathogen Mycosphaerella graminicola is characterized by high nuclear diversity, low mitochondrial diversity, regular recombination, and gene flow. Fungal Genet. Biol. 38:286-297.

Zhong, Z., Marcel, T. C., Hartmann, F. E., Ma, X., Plissonneau, C., Zala, M., Ducasse, A., Confais, J., Compain, J., Lapalu, N., Amselem, J., McDonald, B. A., Croll, D., and Palma-Guerrero, J. 2017. A small secreted protein in Zymoseptoria tritici is responsible for avirulence on wheat cultivars carrying the Stb6 resistance gene. New Phytol. 214:619-631. 